\title{
BMJ Open Workplace violence, job satisfaction, burnout, perceived organisational support and their effects on turnover intention among Chinese nurses in tertiary hospitals: a cross-sectional study
}

\author{
Wenhui Liu, ${ }^{1}$ Shihong Zhao, ${ }^{1,2}$ Lei Shi, ${ }^{1}$ Zhong Zhang, ${ }^{3}$ Xinyan Liu, ${ }^{3} \mathrm{Li} \mathrm{Li},{ }^{1}$ \\ Xiaojian Duan, ${ }^{1}$ Guoqiang Li, ${ }^{1}$ Fengge Lou, ${ }^{4}$ Xiaoli Jia, ${ }^{5}$ Lihua Fan, ${ }^{1,3}$ Tao Sun, ${ }^{1,3}$ \\ $\mathrm{Xin} \mathrm{Ni}^{6}$
}

To cite: Liu W, Zhao S, Shi L, et al. Workplace violence, job satisfaction, burnout, perceived organisational support and their effects on turnover intention among Chinese nurses in tertiary hospitals: a crosssectional study. BMJ Open 2018;8:e019525. doi:10.1136/ bmjopen-2017-019525

- Prepublication history for this paper is available online. To view these files, please visit the journal online (http://dx.doi. org/10.1136/bmjopen-2017019525).

WL, SZ and LS contributed equally.

Received 8 September 2017 Revised 13 March 2018 Accepted 19 April 2018
Check for updates

For numbered affiliations see end of article.

Correspondence to

Professor Lihua Fan; lihuafan@126.com and

Prof. Tao Sun;

hydsunta0@126.com

\section{ABSTRACT}

Objectives Our aims were to assess the relationship between workplace violence, job satisfaction, burnout, organisational support and turnover intention, and to explore factors associated with turnover intention among nurses in Chinese tertiary hospitals.

Methods The purposive sampling method was used to collect data from August 2016 through January 2017.

A total of 1761 nurses from 9 public tertiary hospitals in 4 provinces (municipalities) located in eastern (Beijing), central (Heilongjiang, Anhui) and western (Shaanxi) regions of China completed the questionnaires (effective response rate $=85.20 \%$ ). A cross-sectional study was conducted using the Workplace Violence Scale, Chinese Maslach Burnout Inventory General Survey, Minnesota Job Satisfaction Questionnaire Revised Short Version, Perceived Organizational Support-Simplified Version Scale and Turnover Intention Scale. Results A total of 1216 of 1706 (69.1\%) participants had high turnover intention. During the previous 12 months, the prevalence of physical violence and psychological violence towards nurses was $9.60 \%$ and $59.64 \%$, respectively. As expected, the level of turnover intention was negatively correlated with participants' scores on job satisfaction $(r=-0.367, p<0.001)$ and perceived organisational support $(r=-0.379, p<0.001)$, respectively. Burnout was positively associated with turnover intention $(r=0.444, p<0.001)$. Workplace violence was positively associated with turnover intention $(\beta=0.035, p<0.001)$ in linear regression analysis. The total effect $(\beta=0.53)$ of workplace violence on turnover intention comprised its direct effect $(\beta=0.36)$ and its indirect effect $(\beta=0.17)$.

Conclusions Perceived organisational support served as a mediator between workplace violence, job satisfaction, burnout and turnover intention, and it had a significantly negative impact on turnover intention. Therefore, nursing managers should understand the importance of the organisation's support and establish a reasonable incentive system to decrease turnover intention.

\section{INTRODUCTION}

A nursing shortage is occurring worldwide and is arousing great concern. ${ }^{1}$ The
Strengths and limitations of this study

- A variety of statistical methods (descriptive analysis, Pearson's correlation analysis, linear regression analysis and structural equation model) were employed to investigate the relationship between independent variables and turnover intention.

- The benefits of using both linear regression and structural equation model include their ability to understand the relationship between variables more clearly and intuitively, and to better master the role of organisational support in the relationship between other variables and turnover intention.

- The retrospective approach to collecting data using self-reports of workplace violence might have led to recall and report bias.

- The results of purposive sampling were greatly influenced by the preconceptions of the researchers; therefore, researchers need to clearly understand the basic characteristics of the population under study.

European Commission reported that there would be shortage of 590000 nurses by the end of $2020 .^{2}$ In the USA, by the end of 2020 , nursing shortage will reach 340000 nurses. ${ }^{3}$ In 2001-2002, the results of the Health Resources Report for the Western Pacific Region on the present situation, shortages and future trends within the world of nursing showed that the ratio of physicians to nurses in Hong Kong, Japan, Thailand, Germany and the UK was more than $1: 4$, and that the ratio of physicians to nurses in Finland, Norway and Canada was over 1:6. ${ }^{4}$ Without a doubt, an inadequate supply of nurses has been a long-existing problem in China. The most recognised cause of nursing shortage seems to be nurses leaving the nursing profession. ${ }^{56}$ Many nurses tend to leave the 
nursing profession and this is regarded as a global political concern. ${ }^{7}$

Turnover intention is defined as the possibility that employees will leave a job within a certain period. ${ }^{8}$ The first study on turnover used the participant determination model proposed by March and Simon in 1958. ${ }^{9}$ Following on from that study, standardised models, for example, the decision-making process model, the employee-withdrawal behaviour model and the intermediate chain extension model, have been constructed, using the peak mutation model, the unfolding model and the loss motivation model. ${ }^{10-14}$ Among these theoretical models and studies, turnover intention has been considered one of the best factors to predict turnover behaviour and has shown significant explanatory power. ${ }^{15}$ Therefore, turnover intention is the focus of this study.

Workplace violence can be divided into physical violence (including hitting, shooting, kicking, slapping, pushing, biting, pinching, wounding using sharp objects, and sexual assault and rape) and psychological violence (including verbal abuse, threats and sexual harassment). ${ }^{16}$ Job satisfaction represents the extent to which personnel's demands and desires are met within the workplace. ${ }^{17}$ Burnout is a syndrome involving emotional exhaustion and depersonalisation and one where personal accomplishments are reduced, resulting in continuous work stress that has not been effectively handled. ${ }^{18}$ Perceived organisational support refers to the overall perception and beliefs of employees about how organisations view their contributions and care about their interests. ${ }^{19}$

In Kim and Kim's ${ }^{20}$ review, it was reported that the mean score for turnover intention among Korean nurses was between 2.40 and 3.85 . About $40 \%$ of the registered nurses in a teaching hospital in Malaysia were reported to have a turnover intention, and the results indicated that age, work experience, nursing education and overall job satisfaction significantly influence an intention to leave. ${ }^{21}$ A survey was conducted in four general hospitals in Seoul, and the findings showed that factors influencing turnover intention involve the organisational system, depersonalisation, physical environment, work role and organisational climate. ${ }^{22}$ A review of the research literature revealed that factors related to the work environment were the most important in respect of nurses' turnover intentions. ${ }^{23} \mathrm{~A}$ study has been conducted among nurses in 1105 general acute care hospitals in Europe and the USA, and showed that the rates of nurse burnout ranged from $10 \%$ to $78 \%$, with the rate of job dissatisfaction ranging from $11 \%$ to $56 \%$ and the rate of intention to leave ranging from $14 \%$ to $49 \%{ }^{24}$

However, turnover intention is usually affected by a variety of factors, for example, work stress, ${ }^{825}$ workplace violence, ${ }^{26}$ job satisfaction, ${ }^{27}$ burnout, ${ }^{27}$ perceived organisational support ${ }^{28}$ and organisational commitment, ${ }^{28}$ among others.

Workplace violence is a widely reported phenomenon among nurses in medical settings, and it influences the turnover intention of nurses. ${ }^{29} \mathrm{~A}$ study indicated that turnover intention was positively associated with exposure types of violence. ${ }^{26} \mathrm{McD}$ owell ${ }^{30}$ found workplace violence to be significantly related to burnout $(\mathrm{r}=0.56, \mathrm{p}<0.01)$ and turnover intention $(\mathrm{r}=0.24, \mathrm{p}<0.01)$ for all direct care paraprofessionals. The previous results determined that a statistically significant relationship existed between turnover intention and workplace violence. ${ }^{31} 32$ Therefore, workplace violence is one of the influential factors in turnover intention. ${ }^{33} 34$

Job satisfaction has been considered as a major contributory factor to intending to stay in a job, in previous studies. ${ }^{23} 2535$ In contrast to this viewpoint, previous studies have also shown that job satisfaction mainly affects turnover intention in respect of organisational commitment. ${ }^{36}$ Furthermore, a third view has shown that two considerations, namely having demands and desires met and organisational commitment, exist simultaneously with regard to job satisfaction and turnover intention. ${ }^{38}$

Moreover, substantial evidence has indicated that employees with high levels of burnout are more prone to turnover intention. ${ }^{32}{ }^{39}$ Some studies have reported that perceived organisational support is a predictor of turnover intention. ${ }^{36} 384041$ One study has indicated that perceived organisational support is negatively associated with turnover intention. ${ }^{42}$

In China, a study from Shanghai indicated that 22.5\% of nurses expressed their intention to leave the emergency department within the following year. ${ }^{43}$ The mean score for turnover intention of intensive care unit nurses was between 1.95 and 2.92 in Shandong. ${ }^{44}$ A survey of turnover intention among 10 tertiary hospitals' nurses in Beijing showed that $16.5 \%$ of nurses may leave the current work unit in the following year. ${ }^{45}$ An investigation in Tianjin showed that work support had a negative influence on turnover intention. ${ }^{46}$ Previous results reflected a significant correlation between psychological capital, work engagement and turnover intention among primary nurses. ${ }^{47}$ Substantial studies have mainly investigated the relationship among job stress, job satisfaction, job engagement, organisational support and turnover intention among Chinese nurses in one province. ${ }^{54-48}$ Therefore, the researchers selected nurses from tertiary hospitals in several provinces and further verified the relationship between workplace violence frequency and turnover intention in this study. This study is novel in that it included organisational support and used both linear regression and structural equation model (SEM).

Based on the above evidence, researchers proposed the present study with the following hypotheses: (1) workplace violence, job satisfaction, burnout and organisational support had different effects on turnover intention; (2) workplace violence had a significant impact on job satisfaction and burnout; (3) organisational support served as a moderator between workplace violence and turnover intention; and (4) organisational support served as a moderator between job satisfaction and burnout.

The present study aims to examine the relationship between workplace violence, job satisfaction, burnout, 
organisational support and turnover intention, and explore factors associated with turnover intention among nurses in Chinese tertiary hospitals.

\section{METHODS}

\section{Participants and sampling}

A cross-sectional study of nurses was conducted from August 2016 through January 2017 in eastern (Beijing), central (Heilongjiang, Anhui) and western (Shaanxi) regions of China. A total of nine public tertiary hospitals in four provinces (municipalities) were selected using the purposive sampling method. The total number of nurses in 9 hospitals (the hospitals were similar in size, department setting and number of nurses) is about 18900 ; a total of 2067 samples were extracted, with these nurses accounting for $10.9 \%$ of the total nurses. On average, 225 nurses from each hospital were extracted (in the actual sampling process, the sample size of each hospital was slightly different, but it was roughly 225 people). All investigators were subject to unified training before starting the investigation and could act as investigators when qualified. Permission to conduct the study was acquired from the managers, and the medical dispute resolution and human resources departments of the hospitals concerned. An anonymous, self-administered questionnaire was used to conduct face-to-face surveys. Paper-andpencil questionnaires were filled out by each participant. Investigators (who were not unit supervisors) conducted the surveys, and they were responsible for explaining the purpose of the study and reminding the participants of the matters to pay attention to in filling out the questionnaire. The two public hospitals in Harbin (the Fourth Affiliated Hospital of Harbin Medical University and the Principal Hospital of Harbin) were selected as the locations for our pre-study before the formal investigation (200 questionnaires were distributed and returned, and these data were excluded in the formal survey data). The investigators and hospital coordinators distributed and took back the questionnaires immediately from the participants. A total of 2067 questionnaires were distributed to nurses, all of which were returned. However, 306 questionnaires were missing data or were blank, which left 1761 valid questionnaires (effective response rate $=85.20 \%$ ). The following conditions were selected as the inclusion criteria for this study: (1) having a practising nurse certificate; (2) having at least 1 year of clinical nursing experience; (3) being still engaged in clinical nursing work during the investigation; and (4) voluntary participation without prejudice to the participants' work. The following were the exclusion criteria: rehire after retirement nurses, refresher nurses and nurses who had not passed the probation period.

\section{Questionnaires}

Demographic characteristics

The demographic information of the nurses was collected, including sex, age, marital status, educational background, professional qualifications, employment form, department, years of experience and daily working hours. Age was categorised as $\leq 30,31-50$ and $\geq 51$ years old. Marital status was categorised as married and single/ divorced/widowed. Educational background was classified as junior college or below, undergraduate, and master's degree or above. Professional qualifications were categorised as primary title, intermediate title and senior title. Employment form was categorised as longterm employee and temporary employee. Department was classified as emergency department, internal medicine, surgery, obstetrics and gynaecology, paediatrics, and others. Work experience was divided into four categories: $\leq 4,5-10,11-20$ and $\geq 21$ years. Daily working time was categorised as $\leq 8,8-10,10-12$ and $\geq 12$ hours.

\section{Workplace Violence Scale}

The Workplace Violence Scale developed by the International Labour Office, the International Council of Nurses, the WHO and the Public Services International Joint Programme on Workplace Violence in the Health Sector in 2003 was used to measure workplace violence. ${ }^{49}$ The scale used in this study consists of two dimensions (physical violence and psychological violence) and has nine items that were adopted from these scales. Each item is scored on a 4-point scale reflecting respondents' frequency of exposure to workplace violence $(0=0$ time, $1=1$ time, $2=2-3$ times and $3=\geq 4$ times). The total possible score ranges from 0 to 27 , with a higher total score indicating a higher frequency of exposure to workplace violence. In the present study, the Cronbach's $\alpha$ for the Workplace Violence Scale was 0.860.

\section{Burnout}

Burnout in the present study was assessed using the Chinese Maslach Burnout Inventory General Survey (CMBI-GS), with a total of 15 items, developed by $\mathrm{Li}$ et al and proven to be valid. ${ }^{50-52}$ The CMBI-GS is categorised into three subscales reflecting job burnout: emotional exhaustion, depersonalisation and reduced personal accomplishment. The response options for each item on the CMBI-GS are rated from 0 (never) to 6 (daily), based on the frequency of occurrence of the specific work feelings of the respondent. The score of the three subscales is equal to the average of the sum of items for each of the subscales. The total possible score is calculated by adding the scores for three subscales, and it ranges from 0 to 18 points, with a higher score indicating a higher level of burnout. In terms of the average score of all items, a score less than 8.5 points indicates lower job burnout, a score of 8.5-14.2 points indicates that burnout is serious, and a score greater than 14.2 points indicates that burnout is extremely serious. In this study, the Cronbach's $\alpha$ for the CMBI-GS was 0.873 . The internal consistency coefficients were $0.834,0.826$ and 0.812 for emotional exhaustion, depersonalisation and reduced personal accomplishment, respectively. 


\section{Job satisfaction}

The Minnesota Job Satisfaction Questionnaire Revised Short Version (MJSQ-RSV) was used in this study to assess participants' satisfaction with their job. ${ }^{53} 54$ The MJSQ-RSV consists of 20 items, including 12 items measuring intrinsic satisfaction and 8 items measuring extrinsic satisfaction. Each item is rated on a 5-point Likert scale ( $1=$ strongly unsatisfied, $2=$ unsatisfied, $3=$ uncertain, $4=$ satisfied and $5=$ stronglysatisfied). Intrinsic satisfaction refers to the degree of satisfaction with the factors involved in the job content. Extrinsic satisfaction refers to the degree of satisfaction of the individual in terms of current job rewards, promotion and leadership style. The higher the participant's self-rating, the higher their satisfaction with the job. The present study revealed that the Cronbach's $\alpha$ for the MJSQ-RSV was 0.882 , and for the two subscales it was 0.872 (intrinsic satisfaction) and 0.896 (extrinsic satisfaction).

\section{Perceived Organizational Support Scale}

Perceived organisational support was measured using the Perceived Organizational Support-Simplified Version Scale (POS-SVS). Previous studies have found the POS-SVS to have high reliability and validity as a measure of perceived organisational support. ${ }^{364155}$ It consists of nine self-report items, which comprise two reverse questions (even if employees try to do the best job they can, the work unit does not notice it; the work unit rarely cares about employees). The other seven items mainly indicate that work unit cares about the well-being and job satisfaction of employees and pays attention to the work goals and values and employees' opinions; employees can get help when they encounter difficulties; and the unit will be proud of what employees have achieved. Each item is rated on a 5-point Likert scale, and ranged from 1 (extremely inconsistent) to 5 (extremely consistent). The total possible score is calculated by adding the scores in all items, and it ranges from 9 to 45 points, with a higher score indicating a higher organisational support. In this study, the Cronbach's $\alpha$ for the POS-SVS was 0.890 .

\section{Turnover Intention Scale}

The Turnover Intention Scale, which has been used to measure turnover intention among nurses, was used in the present study. The Turnover Intention Scale was developed by Lee and $\mathrm{Lee}^{56}$ and has been widely used in many studies. ${ }^{845} 46$ This six-item scale is divided into three dimensions: the possibility of an employee quitting his/her present job, the motivation for employees to find other jobs and the possibility of employees having access to external work. Each item is scored on a 4-point scale reflecting participants' intention to leave ( $1=$ never, $2=$ seldom, $3=$ occasionally and $4=$ often $)$. The total possible score is counted by adding the scores in all items, and it ranges from 6 to 24 points, with a higher score indicating a stronger intention to leave. The extent of turnover intention is divided into four levels according to the different total average score of turnover intention. A total average score $\leq 1$ indicates that turnover intention is particularly low, less low when it is from 1 to 2 , higher when it is from 2 to 3 , and exceptionally high when it is greater than 3 . In the present study, the Cronbach's $\alpha$ for the Turnover Intention Scale was 0.862 .

\section{Data analysis}

EpiData V.3.1 was used to establish the study's database. Missing data or poor-quality questionnaires were eliminated. To ensure accuracy, two trained personnel entered the data after all the surveys were completed. IBM SPSS V.19.0 was used for data analysis. Descriptive statistics, including number $(\mathrm{n})$, percentages $(\%)$, mean and $\mathrm{SD}$, were calculated for the demographic variables. We used one-way analysis of variance or independent sample t-tests to compare group differences on the measurements of the continuous variables. Pearson's correlations were used to examine correlations among the continuous variables. Linear regression analysis was used to examine the associations of the demographic variables and workplace violence, job satisfaction, burnout, perceived organisational support and turnover intention variables. Statistics including $F$ values, $\mathrm{R}^{2}, \mathrm{R}^{2}$-changes $\left(\Delta \mathrm{R}^{2}\right)$, standardised regression coefficients $(\beta)$ and $p$ values for each step in the regression model were reported. All study variables were tested for multicollinearity. A p value $<0.05$ was considered statistically significant.

Path analysis was used to examine the relationship among the five variables, namely workplace violence, job satisfaction, burnout, perceived organisational support and turnover intention. An SEM for path analysis was constructed using the AMOS V.17.0 program to analyse the effects of workplace violence on job satisfaction, burnout, perceived organisational support and turnover intention. The model was considered to have a good fit when all path coefficients were significant at the level of $0.05 ; \chi^{2} / \mathrm{df}$ was below 5 ; the standardised root mean square residual was below 0.08 ; the root mean square error of approximation was below 0.08 ; the root mean square residual was below 0.10; and the goodness of fit index, the normed fit index, Tucker-Lewis incremental fit and comparative fit index were $\geq 0.90$.

\section{STROBE statement}

The STROBE (Strengthening the Reporting of Observational Studies in Epidemiology) guidelines are followed in this study.

\section{Patient and public involvement statement}

There are no patients or public participation in this study.

\section{Ethical considerations}

Informed consent was obtained from each hospital and the nurses involved in the investigation. All participants gave their informed consent before the survey; they were assured that their personal information would be kept confidential. 


\begin{tabular}{|c|c|c|}
\hline Demographic variables & $\mathbf{n}$ & $\%$ \\
\hline \multicolumn{3}{|l|}{ Gender } \\
\hline Male & 60 & 3.4 \\
\hline Female & 1701 & 96.6 \\
\hline \multicolumn{3}{|l|}{ Age group (years) } \\
\hline$\leq 30$ & 899 & 51.1 \\
\hline $31-50$ & 793 & 45.0 \\
\hline$\geq 51$ & 69 & 3.9 \\
\hline \multicolumn{3}{|l|}{ Level of education } \\
\hline Below undergraduate & 715 & 40.6 \\
\hline Undergraduate & 1020 & 57.9 \\
\hline Master's degree or above & 26 & 1.5 \\
\hline \multicolumn{3}{|l|}{ Marital status } \\
\hline Married & 1128 & 64.1 \\
\hline Single/divorced/widowed & 633 & 35.9 \\
\hline \multicolumn{3}{|l|}{ Professional qualifications } \\
\hline Primary title & 1161 & 65.9 \\
\hline Intermediate title & 528 & 30.0 \\
\hline Senior title & 72 & 4.1 \\
\hline \multicolumn{3}{|l|}{ Employment form } \\
\hline Long-term employee & 693 & 39.4 \\
\hline Temporary employee & 1068 & 60.6 \\
\hline \multicolumn{3}{|l|}{ Department } \\
\hline Emergency department & 299 & 17.0 \\
\hline Internal medicine & 559 & 31.7 \\
\hline Surgery & 543 & 30.8 \\
\hline Obstetrics and gynaecology & 93 & 5.3 \\
\hline Paediatrics & 101 & 5.7 \\
\hline ENT & 82 & 4.7 \\
\hline Other & 84 & 4.8 \\
\hline
\end{tabular}

\section{Years of experience}

\begin{tabular}{lrr}
$\leq 4$ & 529 & 30.0 \\
$5-10$ & 619 & 35.2 \\
$11-20$ & 346 & 19.6 \\
$\geq 21$ & 267 & 15.2 \\
Daily working hours & & \\
$\leq 8$ & 113 & 6.4 \\
$8-10$ & 1485 & 84.3 \\
$10-12$ & 126 & 7.2 \\
$\geq 12$ & 37 & 2.1 \\
\hline
\end{tabular}

ENT, eyes, nose and throat.

\section{RESULTS}

\section{Demographic characteristics of the participants}

The demographic characteristics of the respondents are shown in table 1 .
Prevalence of workplace violence in the preceding 12 months During the previous 12 months, the prevalence of physical violence and psychological violence towards nurses was $9.60 \%(169 / 1761)$ and $59.64 \%(1111 / 1761)$, respectively. In the past year, respondents reported an exposure frequency of workplace violence of less than or equal to 3 , accounting for $65.9 \%$ of all incidents. The respondents reported that patients' relatives were the main perpetrators $(71.2 \%, \mathrm{n}=797)$, followed by the patients $(25.4 \%$, $\mathrm{n}=284)$.

\section{The difference between participants' characteristics and the multiple variables score}

Table 2 shows the descriptive association between respondents' characteristics and the burnout, job satisfaction, workplace violence, perceived organisational support and turnover intention scores. There was a significant difference in the score on turnover intention among characteristics involving age group, educational level, different professional titles, employment form, department, years of experience and daily working hours for nurses in the tertiary hospitals.

\section{Pearson's correlations between different measurement variables}

Table 3 shows the correlations among the respondents' turnover intention and scores on workplace violence, burnout, job satisfaction and perceived organisational support. As expected, the level of turnover intention was positively correlated with respondents' scores on workplace violence $(\mathrm{r}=0.122, \mathrm{p}<0.001)$. Burnout was positively associated with turnover intention $(\mathrm{r}=0.444, \mathrm{p}<0.001)$. The level of turnover intention was negatively correlated with participants' scores on job satisfaction $(r=-0.367$, $\mathrm{p}<0.001)$ and perceived organisational support $(\mathrm{r}=-0.379$, $\mathrm{p}<0.001)$, respectively.

\section{Linear regression analysis and path analysis of factors related} to turnover intention

The predicting factors of turnover intention are presented in table 4. Demographic variables that were significantly related to turnover intention were used as control variables. Demographic variables alone explained less than $3 \%$ of the overall variance in turnover intention. As shown in block 2, workplace violence was positively associated with turnover intention $(\beta=0.034, p<0.001)$. It explained another $2 \%$ of the overall variance in turnover intention. In block 3, with the addition of organisational support to the model, the explained variance jumped to $13 \%$, meaning that it was this factor that explained most of the variance. Extrinsic satisfaction added another 3\%, while emotional exhaustion and depersonalisation contributed nearly $9 \%$. Furthermore, it should be noted that professional qualifications were significant in every step except in the final step, when burnout was added to the model. It was interesting that employment form was significant throughout. 
Table 2 Burnout, job satisfaction, workplace violence, perceived organisational support and turnover intention according to general characteristics

\begin{tabular}{|c|c|c|c|c|c|}
\hline & Burnout & Job satisfaction & $\begin{array}{l}\text { Workplace } \\
\text { violence }\end{array}$ & $\begin{array}{l}\text { Perceived } \\
\text { organisational } \\
\text { support } \\
\end{array}$ & $\begin{array}{l}\text { Turnover } \\
\text { intention }\end{array}$ \\
\hline Characteristics & $\mathrm{M} \pm \mathrm{SD}$ & $\mathrm{M} \pm \mathrm{SD}$ & $\mathrm{M} \pm \mathrm{SD}$ & $\mathrm{M} \pm \mathrm{SD}$ & $\mathrm{M} \pm \mathrm{SD}$ \\
\hline \multicolumn{6}{|l|}{ Gender } \\
\hline Male & $6.23 \pm 3.34$ & $3.54 \pm 0.55$ & $3.15 \pm 3.92$ & $3.27 \pm 0.57$ & $2.30 \pm 0.71$ \\
\hline Female & $6.53 \pm 3.08$ & $3.52 \pm 0.54$ & $2.11 \pm 2.60$ & $3.10 \pm 0.64$ & $2.40 \pm 0.60$ \\
\hline$F / \mathrm{t}$ & -0.757 & 0.256 & $8.931^{* *}$ & $1.991^{*}$ & -1.263 \\
\hline \multicolumn{6}{|l|}{ Age group (years) } \\
\hline$\leq 30$ & $6.58 \pm 3.03$ & $3.54 \pm 0.54$ & $1.81 \pm 2.38$ & $3.13 \pm 0.64$ & $2.44 \pm 0.61$ \\
\hline $31-50$ & $6.53 \pm 3.16$ & $3.50 \pm 0.55$ & $2.36 \pm 2.73$ & $3.07 \pm 0.65$ & $2.39 \pm 0.60$ \\
\hline$\geq 51$ & $5.80 \pm 3.07$ & $3.55 \pm 0.52$ & $3.97 \pm 4.09$ & $3.14 \pm 0.57$ & $2.04 \pm 0.56$ \\
\hline$F / \mathrm{t}$ & 2.040 & 1.672 & $26.537^{\star *}$ & 1.986 & $14.144^{\star *}$ \\
\hline \multicolumn{6}{|l|}{ Level of education } \\
\hline Below undergraduate & $6.62 \pm 3.01$ & $3.52 \pm 0.54$ & $1.96 \pm 2.45$ & $3.11 \pm 0.61$ & $2.38 \pm 0.63$ \\
\hline Undergraduate & $6.48 \pm 3.13$ & $3.53 \pm 0.55$ & $2.26 \pm 2.77$ & $3.10 \pm 0.65$ & $2.42 \pm 0.58$ \\
\hline Master's degree or above & $5.54 \pm 3.40$ & $3.58 \pm 0.54$ & $2.58 \pm 3.76$ & $3.27 \pm 0.78$ & $2.08 \pm 0.61$ \\
\hline$F / \mathrm{t}$ & 1.737 & 0.202 & $3.161^{*}$ & 0.888 & $4.468^{\star}$ \\
\hline \multicolumn{6}{|l|}{ Marital status } \\
\hline Married & $6.45 \pm 3.12$ & $3.52 \pm 0.54$ & $2.25 \pm 2.69$ & $3.10 \pm 0.65$ & $2.38 \pm 0.60$ \\
\hline Single/divorced/widowed & $6.65 \pm 3.03$ & $3.53 \pm 0.56$ & $1.96 \pm 2.61$ & $3.12 \pm 0.63$ & $2.43 \pm 0.61$ \\
\hline$F / \mathrm{t}$ & -1.304 & -0.203 & $4.789^{\star}$ & -0.843 & -1.658 \\
\hline \multicolumn{6}{|l|}{ Professional title } \\
\hline Primary title & $6.67 \pm 3.04$ & $3.53 \pm 0.54$ & $1.90 \pm 2.38$ & $3.11 \pm 0.65$ & $2.45 \pm 0.60$ \\
\hline Intermediate title & $6.42 \pm 3.17$ & $3.49 \pm 0.56$ & $2.57 \pm 3.05$ & $3.07 \pm 0.62$ & $2.31 \pm 0.61$ \\
\hline Senior title & $4.87 \pm 2.77$ & $3.70 \pm 0.50$ & $2.86 \pm 3.34$ & $3.25 \pm 0.68$ & $2.17 \pm 0.59$ \\
\hline$F / t$ & $12.077^{* *}$ & $4.781^{* *}$ & $14.412^{* *}$ & 2.735 & $15.543^{\star *}$ \\
\hline \multicolumn{6}{|l|}{ Employment form } \\
\hline Long-term employee & $6.71 \pm 3.30$ & $3.48 \pm 0.57$ & $2.46 \pm 2.80$ & $3.05 \pm 0.65$ & $2.32 \pm 0.60$ \\
\hline Temporary employee & $6.40 \pm 2.94$ & $3.55 \pm 0.52$ & $1.93 \pm 2.55$ & $3.14 \pm 0.63$ & $2.45 \pm 0.61$ \\
\hline$F / \mathrm{t}$ & $2.025^{\star}$ & $-2.460^{*}$ & $16.717^{\star \star}$ & $-2.779^{\star \star}$ & $-4.377^{\star \star}$ \\
\hline \multicolumn{6}{|l|}{ Department } \\
\hline Emergency department & $6.51 \pm 3.21$ & $3.51 \pm 0.60$ & $2.60 \pm 3.05$ & $3.12 \pm 0.70$ & $2.37 \pm 0.63$ \\
\hline Internal medicine & $6.40 \pm 3.06$ & $3.55 \pm 0.55$ & $1.90 \pm 2.38$ & $3.15 \pm 0.64$ & $2.38 \pm 0.60$ \\
\hline Surgery & $6.73 \pm 3.05$ & $3.50 \pm 0.54$ & $2.00 \pm 2.47$ & $3.05 \pm 0.63$ & $2.45 \pm 0.59$ \\
\hline Obstetrics and gynaecology & $6.19 \pm 2.71$ & $3.54 \pm 0.50$ & $2.65 \pm 3.31$ & $3.13 \pm 0.58$ & $2.44 \pm 0.56$ \\
\hline Paediatrics & $7.09 \pm 3.23$ & $3.47 \pm 0.51$ & $2.40 \pm 2.76$ & $3.08 \pm 0.64$ & $2.35 \pm 0.67$ \\
\hline ENT & $5.87 \pm 3.20$ & $3.56 \pm 0.48$ & $1.74 \pm 2.31$ & $3.12 \pm 0.62$ & $2.25 \pm 0.54$ \\
\hline Other & $6.36 \pm 3.13$ & $3.55 \pm 0.55$ & $2.58 \pm 3.29$ & $3.11 \pm 0.57$ & $2.32 \pm 0.66$ \\
\hline$F / \mathrm{t}$ & 1.938 & 0.639 & $3.905^{\star}$ & 1.211 & $2.234^{*}$ \\
\hline \multicolumn{6}{|l|}{ Years of experience } \\
\hline$\leq 4$ & $6.26 \pm 2.78$ & $3.60 \pm 0.51$ & $1.70 \pm 2.56$ & $3.21 \pm 0.58$ & $2.37 \pm 0.57$ \\
\hline $5-10$ & $6.88 \pm 3.18$ & $3.49 \pm 0.55$ & $2.22 \pm 2.65$ & $3.06 \pm 0.67$ & $2.49 \pm 0.63$ \\
\hline $11-20$ & $6.75 \pm 3.10$ & $3.45 \pm 0.58$ & $2.28 \pm 2.54$ & $3.04 \pm 0.67$ & $2.46 \pm 0.59$ \\
\hline$\geq 21$ & $5.94 \pm 3.33$ & $3.53 \pm 0.53$ & $2.66 \pm 2.92$ & $3.08 \pm 0.65$ & $2.18 \pm 0.58$ \\
\hline$F / t$ & $7.859^{\star \star}$ & $6.249^{\star \star}$ & $8.745^{\star \star}$ & $6.690^{\star \star}$ & $18.233^{\star \star}$ \\
\hline
\end{tabular}

Continued 


\begin{tabular}{|c|c|c|c|c|c|}
\hline & Burnout & Job satisfaction & $\begin{array}{l}\text { Workplace } \\
\text { violence }\end{array}$ & $\begin{array}{l}\text { Perceived } \\
\text { organisational } \\
\text { support }\end{array}$ & $\begin{array}{l}\text { Turnover } \\
\text { intention }\end{array}$ \\
\hline Characteristics & $\mathrm{M} \pm \mathrm{SD}$ & $\mathrm{M} \pm \mathrm{SD}$ & $\mathrm{M} \pm \mathrm{SD}$ & $\mathrm{M} \pm \mathrm{SD}$ & $\mathrm{M} \pm \mathrm{SD}$ \\
\hline \multicolumn{6}{|c|}{ Daily working hours } \\
\hline$\leq 8$ & $6.08 \pm 3.01$ & $3.65 \pm 0.51$ & $2.20 \pm 2.96$ & $3.25 \pm 0.69$ & $2.24 \pm 0.59$ \\
\hline $8-10$ & $6.53 \pm 3.09$ & $3.52 \pm 0.55$ & $2.09 \pm 2.55$ & $3.10 \pm 0.64$ & $2.41 \pm 0.60$ \\
\hline$\geq 12$ & $7.11 \pm 3.71$ & $3.49 \pm 0.58$ & $4.14 \pm 4.58$ & $3.10 \pm 0.62$ & $2.37 \pm 0.68$ \\
\hline$F / \mathrm{t}$ & 1.415 & $3.096^{\star}$ & $7.195^{\star \star}$ & 2.229 & $2.826^{\star}$ \\
\hline
\end{tabular}

${ }^{*} \mathrm{P}<0.05,{ }^{* *} \mathrm{p}<0.01$.

ENT, ear, nose and throat; $M$, mean.

Path analysis using the SEM was performed, which is shown in figure 1. Workplace violence had a negative effect on job satisfaction, which was mediated through perceived organisational support. The total effect $(\beta=-0.19)$ of workplace violence on job satisfaction comprised its direct effect $(\beta=-0.12)$ and its indirect effect $(\beta=-0.07=-0.13 \times 0.50)$, mediated through perceived organisational support. The total effect $(\beta=0.53)$ of workplace violence on turnover intention comprised its direct effect $(\beta=0.36)$ and its indirect effect $(\beta=0.17=(-0.12) \times 0.19+(-0.13) \times(-1.05)+0.25 \times(-$ $0.17) \times(-1.05)+(-0.13) \times 0.50 \times(-0.19))$. Job satisfaction was negatively associated with burnout. On the other hand, job burnout was positively related to turnover intention. The squared multiple correlations value was 0.432 , which implies that the built SEM explained $43.2 \%$ of the total variance of turnover intention.

\section{DISCUSSION}

Although different measurement tools for turnover intention were used in different studies, the average scores and percentages of perceived high turnover intention have been used as a reference for measuring potential turnover behaviour. ${ }^{57}$ The total mean score of overall perception of turnover intention is greater than 2 points, which means that the turnover intention of nurses is high. Based on this standard, 545 participants had a low turnover intention, but $1216(69.1 \%)$ participants had a high turnover intention. Meanwhile, a total of 291 of the 1216 nurses (23.9\%) with a higher turnover intention tended to want to leave more strongly (mean score of turnover intention $>3$ ). The Chinese nurses intending to leave their current profession was higher than in Malaysia, ${ }^{21}$ America, ${ }^{24}$ Finland ${ }^{24}$ and Greece. ${ }^{24}$ The reason for this phenomenon may be attributed to two aspects. On the one hand, nursing is a professional, intellectual and practical specialty. With the increase in social demand for nurses, nurses have certain advantages in obtaining employment. They can more readily find jobs, which increases the likelihood of nurses leaving their current jobs. On the other hand, the contradiction between the low social status of nurses and

Table 3 Pearson's correlations among workplace violence, burnout, job satisfaction, perceived organisational support and turnover intention

\begin{tabular}{|c|c|c|c|c|c|c|c|c|c|c|}
\hline Variables & 1 & 2 & 3 & 4 & 5 & 6 & 7 & 8 & 9 & 10 \\
\hline 2. Workplace violence & $0.122^{\star \star}$ & 1 & & & & & & & & \\
\hline 4. Emotional exhaustion & $0.418^{\star \star}$ & $0.213^{\star \star}$ & $0.792^{\star \star}$ & 1 & & & & & & \\
\hline 5. Depersonalisation & $0.460^{\star *}$ & $0.220^{\star \star}$ & $0.846^{\star \star}$ & $0.754^{\star \star}$ & 1 & & & & & \\
\hline $\begin{array}{l}\text { 7. Perceived organisational } \\
\text { support }\end{array}$ & $-0.379^{\star *}$ & $-0.172^{\star *}$ & $-0.527^{\star \star}$ & $-0.445^{\star \star}$ & $-0.495^{\star *}$ & $-0.216^{\star \star}$ & 1 & & & \\
\hline 8. Job satisfaction & $-0.367^{\star \star}$ & $-0.188^{\star \star}$ & $-0.562^{\star \star}$ & $-0.478^{\star \star}$ & $-0.524^{\star \star}$ & $-0.231^{\star \star}$ & $0.675^{\star \star}$ & 1 & & \\
\hline 9. Intrinsic satisfaction & $-0.330^{\star \star}$ & $-0.171^{\star \star}$ & $-0.532^{\star *}$ & $-0.441^{\star *}$ & $-0.493^{\star \star}$ & $-0.232^{*}$ & $0.626^{\star *}$ & $0.946^{\star *}$ & 1 & \\
\hline
\end{tabular}

${ }^{\star} \mathrm{P}<0.05,{ }^{* *} \mathrm{p}<0.01$. 
Table 4 Predicting factors of turnover intention

\begin{tabular}{|c|c|c|c|c|c|}
\hline Variables & Block $1(\beta)$ & Block $2(\beta)$ & Block $3(\beta)$ & Block $4(\beta)$ & Block $5(\beta)$ \\
\hline Age group & -0.055 & $-0.076^{*}$ & -0.055 & -0.055 & -0.051 \\
\hline Level of education & 0.028 & 0.022 & 0.028 & 0.025 & 0.026 \\
\hline Professional qualifications & $0.120^{* *}$ & $0.128^{\star *}$ & $0.098^{\star *}$ & $0.095^{\star \star}$ & 0.044 \\
\hline Employment form & $0.081^{*}$ & $0.087^{*}$ & $0.108^{* *}$ & $0.098^{* \star}$ & $0.146^{* *}$ \\
\hline Department & 0.008 & 0.011 & 0.010 & 0.011 & 0.007 \\
\hline Years of experience & 0.034 & 0.038 & 0.014 & 0.006 & 0.001 \\
\hline Daily working hours & 0.056 & 0.046 & 0.030 & 0.012 & 0.009 \\
\hline Workplace violence & & $0.034^{* *}$ & $0.019^{\star \star}$ & $0.016^{\star \star}$ & 0.005 \\
\hline Organisational support & & & $-0.039^{* *}$ & $-0.022^{\star *}$ & $-0.012^{\star *}$ \\
\hline Intrinsic satisfaction & & & & 0.001 & $0.008^{*}$ \\
\hline Extrinsic satisfaction & & & & $-0.037^{\star \star}$ & $-0.030^{\star \star}$ \\
\hline Emotional exhaustion & & & & & $0.051^{* *}$ \\
\hline Depersonalisation & & & & & $0.113^{* *}$ \\
\hline Reduced personal accomplishment & & & & & 0.004 \\
\hline$F$ & $6.374^{\star \star}$ & $10.553^{\star *}$ & $41.686^{\star *}$ & $41.863^{\star *}$ & $51.582^{\star *}$ \\
\hline $\mathrm{R}^{2}$ & 0.025 & 0.046 & 0.176 & 0.208 & 0.293 \\
\hline$\Delta \mathrm{R}^{2}$ & $0.025^{\star *}$ & $0.021^{\star *}$ & $0.130^{* *}$ & $0.032^{\star \star}$ & $0.085^{\star \star}$ \\
\hline
\end{tabular}

${ }^{*} \mathrm{P}<0.05,{ }^{* *} \mathrm{p}<0.01$.

patient expectations is becoming a prominent problem in China's medical environment, leading to a crisis of confidence. It is worth noting that historical reasons have led to low status and poor professional recognition of Chinese nurses. However, patients place high demands on the level of health services provided by nurses. This significant contrast between expectations and reality can easily lead to nurses' resignations. Based on the present study, more attention needs to be paid to nurses in China to reduce their turnover intention.

According to linear regression analysis, block 1 showed that professional qualifications and employment form are two important demographic variables that affect nurses'

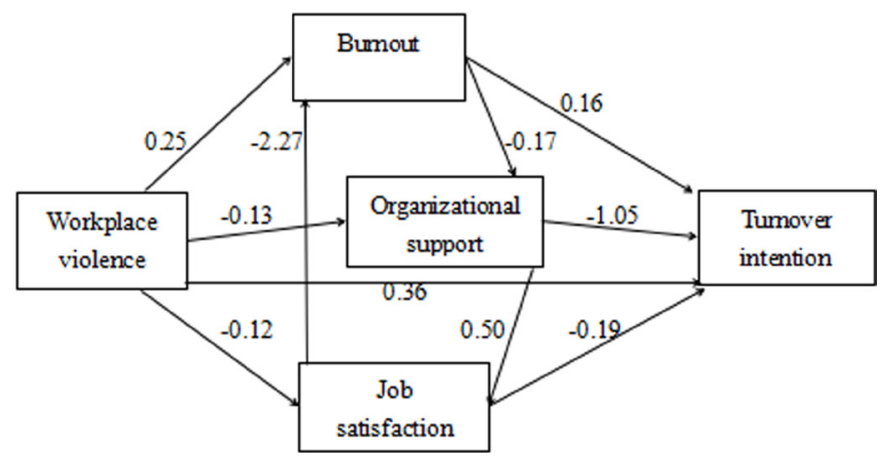

Figure 1 The final model in this study $(\mathrm{CFI}=0.956$, $\mathrm{GFI}=0.924, \mathrm{IFI}=0.942, \mathrm{NFI}=0.931, \mathrm{RMR}=0.050$,

RMSEA=0.053, TLI=0.926). CFI, comparative fit index; GFI, goodness of fit index; IFI, incremental fit index; NFI, normed fit index; RMR, root mean square residual; RMSEA, root mean square error of approximation; TLI, Tucker-Lewis incremental fit. turnover intention, which is different from the findings of Almalki et al's study. ${ }^{58}$ The results of a single factor analysis indicated that nurses with lower level professional qualifications had a higher turnover intention, and full-time employed nurses had a lower turnover intention than temporarily employed nurses. This may be attributed to nurses with low professional qualifications being generally in first-line clinical work, facing a heavy workload and finding it difficult to cope with the patients or their relatives. They are confronted with an imbalance between pay and return, as well as social ignorance of their role, which affects their work enthusiasm and thereby increasing the possibility of leaving. In addition, the temporarily employed nurses' income is unstable, and these nurses do not have a strong sense of belonging to the hospital, so a turnover intention possibility is stronger.

In the linear regression analysis, block 2 showed that workplace violence is one of the significant predictors of turnover intention, which is consistent with earlier findings. ${ }^{30-34}$ Workplace violence is a particularly shocking event within our model. Workplace violence causes physical and psychological harm to nurses ${ }^{59}$ and aggravates nurses' stress and reluctance to work, ${ }^{16}$ resulting in an increase in turnover intention. Meanwhile, workplace violence can provoke in nurses a sense of extreme insecurity and reduced self-value, which may directly lead to turnover intention. The results of linear regression analysis also demonstrated that emotional exhaustion and depersonalisation had a positively significant influence on turnover intention, and they explained $9 \%$ of the overall variance in turnover intention. In short, our 
findings showed that job burnout is positively related to turnover intention, which is similar to previous results. $^{21} 272938$ Clinical nurses often undertake overloaded work, and especially young nurses who have just started work, have relatively insufficient clinical technical ability and effective communication skills. When their behaviour is different from the expectations of doctors/ administrators/patients, the doctor/manager's criticism and the patient's dissatisfaction will reduce their work enthusiasm and easily lead to emotional exhaustion, causing turnover intention. Another noteworthy result of our study was that job satisfaction was found to be negatively related to turnover intention in the SEM and Pearson's correlation analysis, similar to previous results. ${ }^{8} 102325$ Therefore, hospitals should pay greater attention to the working conditions and health status of nurses and increase their job satisfaction and sense of organisational belongingness to reduce their turnover intention.

Organisational support explained $13 \%$ of the overall variance in turnover intention with regard to the results of the linear regression, and it was the most significant predictor of turnover intention. The results of the SEM also showed that organisational support has a direct or indirect effect on turnover intention. These results suggested that organisational support makes the greatest contribution to the model of turnover intention, which were similar to previous findings. ${ }^{36}$ The psychological mechanism embodied in the perceived organisational support is the social exchange between employees and organisations. ${ }^{60}$ From the view of social exchange, the exchange consciousness of employees on perceived organisational support depends entirely on the level of that organisational support. The fundamental reason employees are willing to stay in an organisation is that they feel the contributions of employees to the organisation are equal or fair in respect of what they receive in return from the relevant organisation. As knowledge workers, nurses generally have higher achievement motivation because they hope to achieve and get social recognition value. When a nurse thinks that hospitals and departments must pay attention to his or her contributions and are concerned about their personal interests and occupation development, this will reduce turnover intention and will lead to a higher organisational commitment and work ability.

Synthesising the results of the linear regression analysis and the SEM showed that perceived organisational support played a mediating role in the relationships between workplace violence, burnout and job satisfaction on turnover intention. This result is a flash point in our study. After workplace violence has occurred, hospitals need to provide care and support to nurses as far as possible to reduce the harm of violence inflicted on them, which in turn is likely to increase their emotional commitment to the hospital and reduce the possibility of leaving. The hospital can set up a psychological decompression room, regularly conduct psychological counselling for nurses through a psychologist and conduct emotional management well. ${ }^{16}$ Hospitals can also provide a series of organisational support to reduce the effect of low job satisfaction and high burnout of nurses on the turnover intention. First, strengthen communication, understand the needs of nurses and take targeted organisational support measures so that nurses can really appreciate hospitals' support; second, pay attention to the work of nurses, provide necessary work resources and condition support for them, pay attention to the problems faced by nurses and try their best to provide help to alleviate nurses' emotional exhaustion and reduce the degree of depersonalisation; and finally, pay attention to the welfare of nurses, implement reasonable salaries and performance incentive system, pay attention to the interests of nurses in decision-making, and at the same time pay attention to the professional development of nurses, and provide more development platforms for nurses so that they can find their own value and personal accomplishment in the process of career development. In brief, the more comprehensive the support provided by the organisation, the less likely the nurses are to have bad emotions.

In conclusion, the hospital should provide active support measures, including giving respect, welfare support and practical support; effectively conveying the support of upper management; ensuring a relationship of trust and support between employees and their immediate supervisors; emphasising procedural justice in the organisation; and creating a supportive organisational climate. ${ }^{19}$ These measures are likely to encourage nurses to stay in their present position, and improve their job satisfaction and reduce their job burnout, thus reducing their turnover rate. $^{3642}$

The SEM results also clearly stated that organisational support serves as a mediator between job satisfaction and burnout. This means that organisational support (paying attention to nurses' feelings and salary benefits) can relieve nurses' job burnout to some extent and then improve their satisfaction with various systems and policies of the organisation. As a reward for the organisation, nurses will also enhance their commitment and loyalty to the organisation and will improve their efforts to work.

The present study has several limitations. First, researchers collected data on whether nurses had experienced workplace violence in the last 12 months, so there may be recall bias in the results. Second, it was not known whether those returning incomplete questionnaires differed in any significant way from those who completed them. Third, purposive sampling results are greatly influenced by the preconceptions of the researchers. To the extent that subjective judgement may be biased, this can readily lead to sampling bias and cannot provide complete confidence in the results of the overall investigation. Thus, the researchers involved clearly understand the basic characteristics of the population under investigation, so that the selected samples can be representative and typical. 


\section{CONCLUSIONS}

Perceived organisational support served as a mediator between workplace violence, job satisfaction, burnout and turnover intention, and it has a significantly negative impact on turnover intention. Therefore, nursing managers should understand the organisation's support and establish a reasonable incentive system to decrease turnover intention.

\section{Author affiliations}

${ }^{1}$ Department of Health Management, Harbin Medical University School of Public Health, Harbin, China

${ }^{2}$ Department of Neurosurgery, The Second Affiliated Hospital of Harbin Medical University, Harbin, China

${ }^{3}$ Department of Medical Education, School of Public Health, Harbin Medical University, Harbin, China

${ }^{4}$ Department of Public Health Research, School of Public Health, Qiqihar Medical University, Qiqihar, China

${ }^{5}$ Department of Autonomous Protection, Chinese Hospital Association, Beijing, China ${ }^{6}$ Department of the Hospital Director, National Center for Children's Health, Beijing Children's Hospital Affiliated to Capital Medical University, Beijing, China

Acknowledgements The authors thank all the nurses, managers and the Chinese Hospital Association for their assistance and support for this project.

Contributors LF, TS and XN designed the study. WL, LS, ZZ, XL, XJ and LL collected the data. WL, SZ, LS, XD, GL, LL and FL analysed the data. WL, SZ and LS drafted the manuscript. WL, LF, TS and XN revised the manuscript.

Funding This study was funded by the National Natural Science Foundation of China (71473063) to LF and also was funded by the Innovative Research Projects of Graduate Students at Harbin Medical University (YJSCX2017-15HYD) to LS.

Competing interests None declared.

Patient consent Obtained.

Ethics approval Ethical approval to conduct this study was granted by the Research Ethics Committee of Harbin Medical University.

Provenance and peer review Not commissioned; externally peer reviewed. Data sharing statement No additional data are available.

Open access This is an Open Access article distributed in accordance with the Creative Commons Attribution Non Commercial (CC BY-NC 4.0) license, which permits others to distribute, remix, adapt, build upon this work non-commercially, and license their derivative works on different terms, provided the original work is properly cited and the use is non-commercial. See: http://creativecommons.org/ licenses/by-nc/4.0/

(c) Article author(s) (or their employer(s) unless otherwise stated in the text of the article) 2018. All rights reserved. No commercial use is permitted unless otherwise expressly granted.

\section{REFERENCES}

1. Nardi DA, Gyurko CC. The global nursing faculty shortage: status and solutions for change. J Nurs Scholarship 2013;45:317-26.

2. Sermeus W, Bruyneel L. Investing in Europe's health workforce of tomorrow: Scope for innovation and collaboration. European Observatory on Health Systems and Policies. Effect of Growth Rate of Load on Strain Aging of Soft Soil in Marsh, 2010:1995-2001.

3. Auerbach DI, Buerhaus PI, Staiger DO. Better late than never: workforce supply implications of later entry into nursing. Health Aff 2007;26:178-85.

4. Xiaoyan W. Analysis of the situation of nursing human resources in public hospitals. The World Clinical Medicine 2016;10:247-8.

5. You L-ming, Ke Y-ying, Zheng J, et al. The development and issues of nursing education in China: A national data analysis. Nurse Educ Today 2015;35:310-4.

6. Janiszewski Goodin $\mathrm{H}$. The nursing shortage in the United States of America: an integrative review of the literature. $J$ Adv Nurs 2003;43:335-43.
7. Anderson DJ, Chan E, Dresner P, et al. Nursing and midwifery services strategic directions, 2011-2015. World Health Organization 2010.

8. Chao M-C, Jou R-C, Liao C-C, et al. Workplace stress, job satisfaction, job performance, and turnover intention of health care workers in rural Taiwan. Asia Pacific Journal of Public Health 2015;27:NP1827-36.

9. March JG, Simon HA. Organizations. New York: Wiley, 1958.

10. Mobley WH, Griffeth RW, Hand HH, et al. Review and conceptual analysis of the employee turnover process. Psychol Bull 1979;86:493-522.

11. Bluedorn AC. A unified model of turnover from organizations. Human Relations 1982;35:135-53.

12. Sheridan JE, Abelson MA. Cusp catastrophe model of employee turnover. Acad Manage J 1983;26:418-36.

13. Lee TW, Mitchell TR. An alternative approach: the unfolding model of voluntary employee turnover. Academy of Management Review 1994;1:51-89.

14. Price JL. The development of a causal model of voluntary turnover. Ames: lowa State University Press, 2000.

15. Griffeth RW, Hom PW, Gaertner S. A meta-analysis of antecedents and correlates of employee turnover: update, moderator tests, and research implications for the next millennium. J Manage 2000;26:463-88.

16. Shi L, Zhang D, Zhou C, et al. A cross-sectional study on the prevalence and associated risk factors for workplace violence against Chinese nurses. BMJ Open 2017;7:e013105.

17. Utriainen $\mathrm{K}$, Kyngäs $\mathrm{H}$. Hospital nurses' job satisfaction: a literature review. J Nurs Manag 2009;17:1002-10.

18. Maslach C, Jackson SE. The measurement of experienced burnout. J Organ Behav 1981;2:99-113.

19. Rhoades L, Eisenberger R. Perceived organizational support: a review of the literature. J Appl Psychol 2002;87:698-714.

20. Kim JK, Kim MJ. A review of research on hospital nurses' turnover intention. J Korean Acad Nurs Adm 2011;17:538.

21. Ramoo V, Abdullah KL, Piaw CY. The relationship between job satisfaction and intention to leave current employment among registered nurses in a teaching hospital. $J$ Clin Nurs 2013;22:3141-52.

22. Yoon G-S, Kim SY. Influences of job stress and burnout on turnover intention of nurses. J Korean Acad Nurs Admin 2010;16:507-16.

23. Coomber B, Louise Barriball K, Barriball KL. Impact of job satisfaction components on intent to leave and turnover for hospitalbased nurses: A review of the research literature. Int J Nurs Stud 2007;44:297-314.

24. Aiken LH, Sermeus W, Van den Heede K, et al. Patient safety, satisfaction, and quality of hospital care: cross sectional surveys of nurses and patients in 12 countries in Europe and the United States. BMJ 2012;344:e1717.

25. Li L, Hu H, Zhou H, et al. Work stress, work motivation and their effects on job satisfaction in community health workers: a crosssectional survey in China. BMJ Open 2014;4:e004897.

26. Choi SH, Lee H. Workplace violence against nurses in Korea and its impact on professional quality of life and turnover intention. $J$ Nurs Manage 2017:1-11.

27. Labrague LJ, McEnroe-Petitte DM, Gloe D, et al. Organizational politics, nurses' stress, burnout levels, turnover intention and job satisfaction. Int Nurs Rev 2017;64:109-16.

28. Oyeleye O, Hanson P, O'Connor N, et al. Relationship of workplace incivility, stress, and burnout on nurses' turnover intentions and psychological empowerment. J Nurs Admin 2013;43:536-42.

29. Seo, Min S K, et al. Effect of workplace bullying, job satisfaction and self-esteem on turnover intention in clinical nurses. Journal of the Korean Society for Wellness 2017;12:105-15.

30. Mcdowell SS. Client-Inflicted workplace violence, burnout, job satisfaction, and turnover intention: a comparative analysis between institution-based and home-based direct care paraprofessionals. Dissertations \& Theses - Gradworks 2015:208.

31. Olsen E, Bjaalid G, Mikkelsen A. Work climate and the mediating role of workplace bullying related to job performance, job satisfaction, and work ability: A study among hospital nurses. $J A d v$ Nurs 2017.

32. Tarja H, Anne K, Marianna V, et al. The prospective effects of workplace violence on physicians' job satisfaction and turnover intentions: the buffering effect of job control. BMC Health Serv Res 2014;14:1-8

33. Christensen MP. Relationships between workplace violence, burnout, and intent to leave in emergency department nurses. Dissertations \& Theses-Gradworks 2014;21:984-90.

34. Kim JI, Kim TS. Violence episodes and turnover among clinical nurses. J Korean Acad Nurs Adm 2004;10:427-36. 
35. Tnay E, Othman AEA, Siong HC, et al. The influences of job satisfaction and organizational commitment on turnover intention. Procedia Soc Behav Sci 2013;97:201-8.

36. Islam T, Latif I, Ali G. The relationship between perceived organizational support and turnover intention: mediating role of affective commitment and job satisfaction. Research Journal of Applied Sciences Engineering \& Technology 2014;8:2422-5.

37. Samad S, Yasmin S, Yusuf M. The role of organizational commitment in mediating the relationship between job satisfaction and turnover intention. European Journal of Social Sciences 2012;30:135-7.

38. Yücel I. Examining the relationships among job satisfaction, organizational commitment, and turnover intention: an empirical study. International Journal of Business and Management 2012;7:1-15.

39. Shimizu T, Feng Q, Nagata S. Relationship between turnover and burnout among japanese hospital nurses. J Occup Health 2005; $47: 334-6$

40. Abou Hashish EA. Relationship between ethical work climate and nurses' perception of organizational support, commitment, job satisfaction and turnover intent. Nurs Ethics 2015:1-16.

41. Dawley D, Houghton JD, Bucklew NS. Perceived organizational support and turnover intention: the mediating effects of personal sacrifice and job fit. J Soc Psychol 2010;150:238-57.

42. Tumwesigye $\mathrm{G}$. The relationship between perceived organizational support and turnover intentions in a developing country: The mediating role of organizational commitment. African Journal of Business Management 2010;4:942-52.

43. Zhang Y, Wu J, Fang Z, et al. Newly graduated nurses' intention to leave in their first year of practice in Shanghai: a longitudinal study. Nurs Outlook 2017;65:202-11.

44. Sun FF, Cp X. Job stress and its relationship with quality of life and turnover intention of ICU nurses in general hospital. Shandong University 2016.

45. Lei W, Hong S, Xin G, et al. Correlation research between nurses' status of career planning and job satisfaction, turnover intention. Chin J Mod Nurs 2015;21:3721-3.

46. Zhang HF, Liu YH, Yang Y, et al. The influencing factors of nurses' turnover tendency. Chinese Journal of Nursing 2015;50:155-60.

47. Hongmei YI, Lanxian YU, Tang J, et al. Relationship between psychological capital, work engagement and turnover intention among primary nurses in traditional Chinese medicine hospitals. Chinese Nursing Management 2015.
48. Li L, Ai H, Gao L, et al. Moderating effects of coping on work stress and job performance for nurses in tertiary hospitals: a cross-sectional survey in China. BMC Health Serv Res 2017;17:401.

49. ILO/ICN/WHO/PSI. Framework guidelines for addressing workplace violence in the health sector. Geneva: ILO/ICN/WHO/PSI, 2002.

50. Richardsen AM, Martinussen M. Factorial validity and consistency of the MBI-GS across occupational groups in Norway. Int $J$ Stress Manag 2005;12:289-97.

51. Li YX, Zhang K, Zhao GX. Confirmatory factor analysis of job burnout. Psychological Exploration 2005;4:70-4.

52. $\mathrm{Cp} \mathrm{L}$, Shi K. The influence of distributive justice and procedural justice on job burnout. Acta Psychologica Sinica 2003;35:677-84.

53. Lin Y, Jing-Xiang MA, Chen WQ, et al. Relationship between perception of job characteristics and job satisfaction of pediatric nurses. Journal of Nursing 2013.

54. Hirschfeld RR. Does revising the intrinsic and extrinsic subscales of the minnesota satisfaction questionnaire short form make a difference? Educ Psychol Meas 2000;60:255-70.

55. Chen ZX, Aryee S, Lee C. Test of a mediation model of perceived organizational support. J Vocat Behav 2005;66:457-70.

56. Lee G, Lee D. A study on the relationships among role conflict, organizational commitment and intent to quit matrix organizational structure: using employees from industrial technology research institute as example. Taiwan: Graduate School of management, National Chiao Tung University, 2000.

57. St G, Huang QM, Chen ZHQ, et al. Relationship between job satisfaction and turnover intention among physicians from three grade hospitals. Chinese Journal of Hospital Administration 2006;9:586-9.

58. Almalki MJ, FitzGerald G, Clark M. The relationship between quality of work life and turnover intention of primary health care nurses in Saudi Arabia. BMC Health Serv Res 2012;12:314.

59. Shi L, Wang L, Jia X, et al. Prevalence and correlates of symptoms of post-traumatic stress disorder among Chinese healthcare workers exposed to physical violence: a cross-sectional study. BMJ Open 2017;7:e016810.

60. Settoon RP, Bennett N, Liden RC. Social exchange in organizations: Perceived organizational support, leader-member exchange, and employee reciprocity. Social Science Electronic Publishing 2014;81:219-27. 